University of Nebraska - Lincoln

DigitalCommons@University of Nebraska - Lincoln

Publications from USDA-ARS / UNL Faculty

U.S. Department of Agriculture: Agricultural

Research Service, Lincoln, Nebraska

2009

Pollen contamination of boll weevil traps

Gretchen D. Jones

United States Department of Agriculture (USDA), g-jones@tamu.edu

Shoil M. Greenberg

United States Department of Agriculture

Follow this and additional works at: https://digitalcommons.unl.edu/usdaarsfacpub

Part of the Agricultural Science Commons

Jones, Gretchen D. and Greenberg, Shoil M., "Pollen contamination of boll weevil traps" (2009).

Publications from USDA-ARS / UNL Faculty. 543.

https://digitalcommons.unl.edu/usdaarsfacpub/543

This Article is brought to you for free and open access by the U.S. Department of Agriculture: Agricultural Research Service, Lincoln, Nebraska at DigitalCommons@University of Nebraska - Lincoln. It has been accepted for inclusion in Publications from USDA-ARS / UNL Faculty by an authorized administrator of DigitalCommons@University of Nebraska - Lincoln. 


\title{
Pollen contamination of boll weevil traps
}

\author{
GRETCHEN D. JONES ${ }^{1} \&$ SHOIL M. GREENBERG ${ }^{2}$ \\ ${ }^{1}$ United States Department of Agriculture, Agriculture Research Service Area-wide Pest Management Research Unit, College \\ Station, TX, USA, ${ }^{2}$ United States Department of Agriculture, Agriculture Research Service, Kika de la Garza Subtropical \\ Agricultural Research Center, Beneficial Insect Research Unit, Weslaco, TX, USA
}

\begin{abstract}
The boll weevil, Anthonomus grandis Boheman, has been the most devastating insect pest of cotton, Gossypium hirsutum L., in the southern United States of America (USA). Although thought to feed only on cotton, the list of non-cotton alternative food sources increases yearly. Many of these taxa are thought to be contaminates and not food sources. The purpose of this research was to examine the possibility that weevils become contaminated with pollen while sitting in the trap. Between January and April, boll weevil traps were placed near Brownsville and Weslaco (a substitute location) and in Santa Ana Wildlife Refuge, Texas. Pollen was removed from the trap's pole, skirt, mesh cone, and lid by wiping them with an individual, sterile, $100 \%$ cellulose acetate filter. The original trap was replaced with a replacement trap that was left for three days, then wiped for pollen. Little pollen was found on the trap parts regardless of the month or the site. The mesh cone was the least contaminated. From these data, it is doubtful that weevils become contaminated with pollen while sitting in the trap. Additional research is needed to examine if pollen is transferred among trapped weevils.
\end{abstract}

Keywords: Boll weevil, trap, pollen contamination

During the twentieth century, the boll weevil, Anthonomus grandis Boheman, was the most devastating insect pest of cotton, Gossypium hirsutum L., in the southern United States of America (USA). Although the Boll Weevil Eradication Program has reduced the impact of this insect pest in the majority of the USA, it is still a threat and periodically reinfests zones where it was thought to be eradicated.

Boll weevils are especially destructive to cotton because the larvae develop and feed on the flowers (squares) and fruits (bolls) of cotton. The damage from the developing larvae usually causes the squares to abort and fall off, and prevent the bolls from maturing and producing cotton fibres.

Adult boll weevils are active year-round in the Lower Rio Grande Valley. In the Lower Rio Grande Valley of Texas, 31 August through 1 February has been established by Texas State Law to be a cotton-free period. The elimination of cotton cropping during this period removes the weevils' food and reproductive source and prevents foraging. This strategy is aimed at reducing the number of weevils overwintering, and so reducing the number of weevils that are available to infest cotton in the spring.

However, adult weevils survive the overwintering period (Leggett \& Fye, 1969) in the Lower Rio Grande Valley. Weevils captured in pheromone traps during overwintering periods suggest that they may be physiologically active and looking for cotton (Bariola et al., 1984). Since seedling cotton is not greatly utilised as a food source by overwintered boll weevils (White \& Rummel, 1978), the weevils must 'wait' until the cotton is flowering before they can feed on flowers, buds, and fruits. Although cotton is not planted during the overwintering period, various cultivated crops exist during this time and throughout

Correspondence: Gretchen D. Jones, Management Research Unit, Area-wide Pest Agriculture Research Service (United States Department of Agriculture), 2771 F and B Road, College Station, Texas 77802, U.S.A. E-mail: g-jones@tamu.edu

This work was authored as part of the Contributor's official duties as an Employee of the United States Government and is therefore a work of the United Government. In accordance with 17 U.S.C. 105, no copyright protection is available for such works under US Law. 
the year. Wild flowers also bloom throughout the overwintering period, not only in fallow fields but also in native habitats, around homes, in city parks, and by roadsides.

Boll weevils are primarily a pollen feeding insect (Cate \& Skinner, 1978). Both the larval and adult stages forage on pollen. Cotton and a few other malvaceous taxa are the main reproductive hosts. Although the larvae are restricted to feeding on cotton, the adult weevils are not restricted to any one plant taxon. Initially, only malvaceous taxa were known as foraging resources for adult boll weevils (Cross et al., 1975; Gaines, 1934; Stoner, 1968; Szumkowski, 1953, 1954). Cate and Skinner (1978) determined that pollen found in a boll weevil's digestive tract could be used to determine the identification of their food sources.

Today, the list of adult foraging resources has expanded to include numerous non-malvaceous taxa (Cate \& Skinner, 1978; Cross et al., 1975; Gaines, 1934; Jones et al., 1992, 1993; Parrott et al., 1989; Rummel et al., 1978; Stoner, 1968; Szumkowski, 1953, 1954). Benedict et al. (1991) found pollen from 15 plant families in the guts of boll weevils captured in southern Texas and north-east Mexico. Pollen from 24 species in 17 non-malvaceous families was identified in boll weevils captured in Brazos County, Texas (Jones, 1997). In three Texas locations, captured boll weevils contained pollen from 58 families, 97 genera, and 46 species (Jones \& Coppedge, 1999). Boll weevils captured in Mississippi contained pollen from 82 families, 132 genera, and 28 species (Hardee et al., 1999). Plant families found in these studies include but are not limited to Asteraceae, Boraginaceae, Euphorbiaceae, Fabaceae, Fagaceae, Papaveraceae, and others.

Non-cotton boll weevil adult food sources have also been examined in countries other than the USA including Mexico (Jones et al., 1992, 1993), Argentina (Cuadrado, 1999; Cuadrado \& Garralla, 2000), Brazil, (Cuadrado, 1996; Gabriel, 2000), and Paraguay (Cuadrado, 1996; Gabriel, 2000). In a province in Argentina that had not grown cotton for five years, over 5000 pollen grains were found in dissected boll weevils (Cuadrado, 2002).

It is apparent from the increasing list of foraging resources, that the adult boll weevil is more of a generalist in its food source selection than previously believed. It is not known if adult boll weevils actively forage on pollen from all of the taxa reported. Some reported taxa are anemophilous (i.e. Quercus spp. [oak] and Pinus spp. [pine]), while other taxa reported are entomophilous (i.e. Helianthus spp. [sunflower] and Sambucus spp. [elderberry]) (Benedict et al., 1991; Jones et al., 1993; Jones, 1997; Jones \& Coppedge, 1996, 1999).
Questions still remain about the food sources of adult weevils. Do the adult weevils actively "seek out" all of the taxa reported? How many of the reported taxa are contaminants? Do adult weevils become contaminated with one pollen type while feeding on the flowers of another? Do adult weevils become contaminated with pollen from non-feeding taxa while sitting in a boll weevil trap? Anemophilous taxa are often considered contaminants, yet some anemophilous taxa seem to be utilised by adult weevils as a food source.

Anemophilous taxa have been examined as a food source. In laboratory studies, two grasses, Setaria sp. (millet) and Sorghum halepense L. (Johnson grass) were fed to adult weevils (Benedict et al., 1991). When these weevils were examined, $70 \%$ of the weevils fed millet contained millet pollen and $50 \%$ of the weevils fed Johnson grass contained Johnson grass pollen. Benedict et al. (1991) suggested that some grass pollen may be potential adult food resources.

Jones (1997) examined the longevity of adult weevils fed an anemophilous taxon, oak pollen. Adult weevils survived over 70 days on only oak pollen as a food source. This was 50 days longer than weevils fed only water.

Jones et al. (2007) examined another anemophilous taxon. They fed adult weevils Amaranthus sp. (pigweed) pollen. They found that after 24 hours, $80 \%$ of the weevils examined contained pigweed pollen in their gut.

These studies certainly show that some anemophilous taxa are used by adult weevils as a food source. However, it is still not known how much pollen contamination occurs. There is nothing in the literature that examines the pollen contamination on a boll weevil trap. The purposes of this research were to examine the amount of pollen contamination on a boll weevil trap and determine the possibility of the weevils becoming contaminated with nonfood pollen while remaining trapped inside.

\section{Material and methods}

\section{Description of study sites}

Initially, two locations were used in the Lower Rio Grande Valley of Texas (LRGV) for this research (Figure 1A). The first was near Brownsville, Texas, (Cameron Co.; Figure 1B) and the second was in Santa Ana Wildlife Refuge (Hidalgo Co.; Figure 1B). The trap was destroyed at Brownsville during March because of work on the drainage ditch near the trap. This work was to continue through April, so a new location was necessary. Since the trap would not be disturbed at the USDA-ARS South Farm, near 

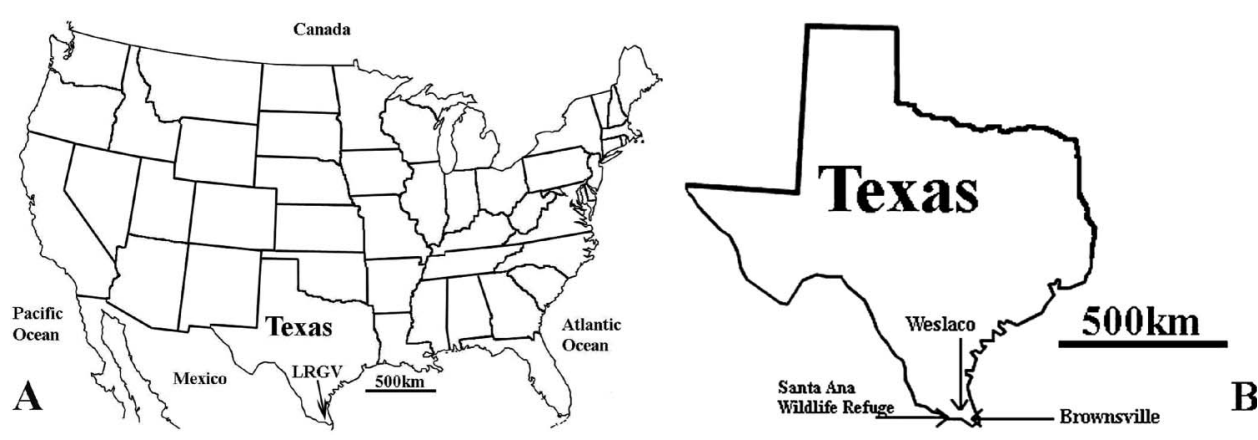

Figure 1. Maps of the United States of America and Texas. A. The entire country and Texas with the Lower Rio Grande Valley (LRGV). B. The State of Texas and the location of the Brownsville, Weslaco, and Santa Ana Wildlife Refuge study sites.

Weslaco, TX (Hidalgo Co.), it was chosen as a replacement site.

The Brownsville and Weslaco sites represented a "normal" positioning of a boll weevil trap. The trap was put at the end of a fallow cotton field. A dirt road ran between the trap and the cotton field. This is typical for boll weevil trap lines so that traps can be regularly checked, weevils removed, and the pheromone wafers replaced. At the Brownsville site there was a drainage ditch about $3 \mathrm{~m}$ from the trap. At Weslaco the drainage ditch was about $500 \mathrm{~m}$ away. East and directly behind the Weslaco trap was a citrus grove and about $700 \mathrm{~m}$ south-west was a pecan [Carya illinoinensis (F. von Wangenheim) K. Koch] orchard.

The drainage ditch at Brownsville contained various native taxa such as ratama (Parkinsonia aculeata L.), spiny hackberry (Celtis pallida J. Torrey), and dry-land willow (Baccharis neglecta N. Britton). Herbaceous taxa included western ragweed ( $\mathrm{Ambro}$ sia psilostachya A. P. de Candolle), various species of grasses (Panicum spp., Aristida spp., Muhlenbergia spp., etc.), sunflower (Helianthus sp.), parthenium (Parthenium sp.), smartweed (Polygonum spp.), and bushy alternate-leaf seedbox (Ludwigia alternifolia L.). The ditch was not overgrown or thick. Some of the vegetation was in flower during the study period.

The drainage ditch in Weslaco contained the same taxa as the ditch near Brownsville. However, the ditch in Weslaco contained more woody taxa including several species of Acacia, lote bush [Ziziphus obtusifolia (W.J. Hooker ex J. Torrey \& A. Gray) A. Gray], white brush [Aloysia gratissima (J. Gillies \& W. J. Hooker) N. Troncoso] and great lead-tree [Leucaena pulverulenta (D. von Schlechtendal) G. Bentham].

The Santa Ana sites represent an opposite vegetational extreme. Two traps were placed in Santa Ana, one on the Old Cemetery Trail and the other near the junction of Bobcat Trail and the paved Refuge Tour Loop. The vegetation in Santa Ana is typical
Tamaulipan Scrub with oaks, mesquite (Prosopis glandulosa J. Torrey), sugar hackberry (Celtis laevigata C. von Willdenow), spiny hackberry, Mexican ash (Fraxinus berlandieriana A. P. de Candolle), and huisache (Acacia farnesiana C. von Willdenow var. farnesiana) (synonym = A. smallii D. Isley) (Correll \& Johnston, 1979). Traps were placed in the open. However, the vegetation around the traps was thick with a higher percentage of woody vs. herbaceous vegetation.

\section{Trap description}

A boll weevil trap assemblage contains several parts (Figure 2), the pole, lid, skirt, and wire mesh cone. The pole is usually metal. It is pounded in the ground and the trap is placed on top of it. The trap is about $25 \mathrm{~cm}$ tall, and when placed onto the pole it is about $1.5 \mathrm{~m}$ from the ground. The skirt and lid are plastic. The skirt is usually green in colour and the lid is clear. The lid has holes in it for air. To lure the weevils to the trap, a small $(1 \mathrm{~cm}$ square) pheromone wafer is placed in the trap on the mesh cone under the lid.

In the centre of the wire mesh cone is a small hole that is large enough for the weevils to pass through and into the lid. A boll weevil usually lands on the lid or skirt, walks downward around the skirt's edge, and then climbs upwards inside the trap towards the light at the mesh cone. Unless the trap contains hundreds of weevils, they will not go back out of the hole and out of the trap.

If weevils are present, the trap is usually removed from the pole, turned upside down, and the lid removed. The weevils are gently tapped or shaken out of the lid and fall into a plastic bag or vial. Once the weevils are removed, the lid is put back on the trap and the trap is put back on the pole. Pheromone wafers are usually replaced every two weeks.

Prior to placement, each trap and pole were cleaned to remove any pollen. Traps and poles were 


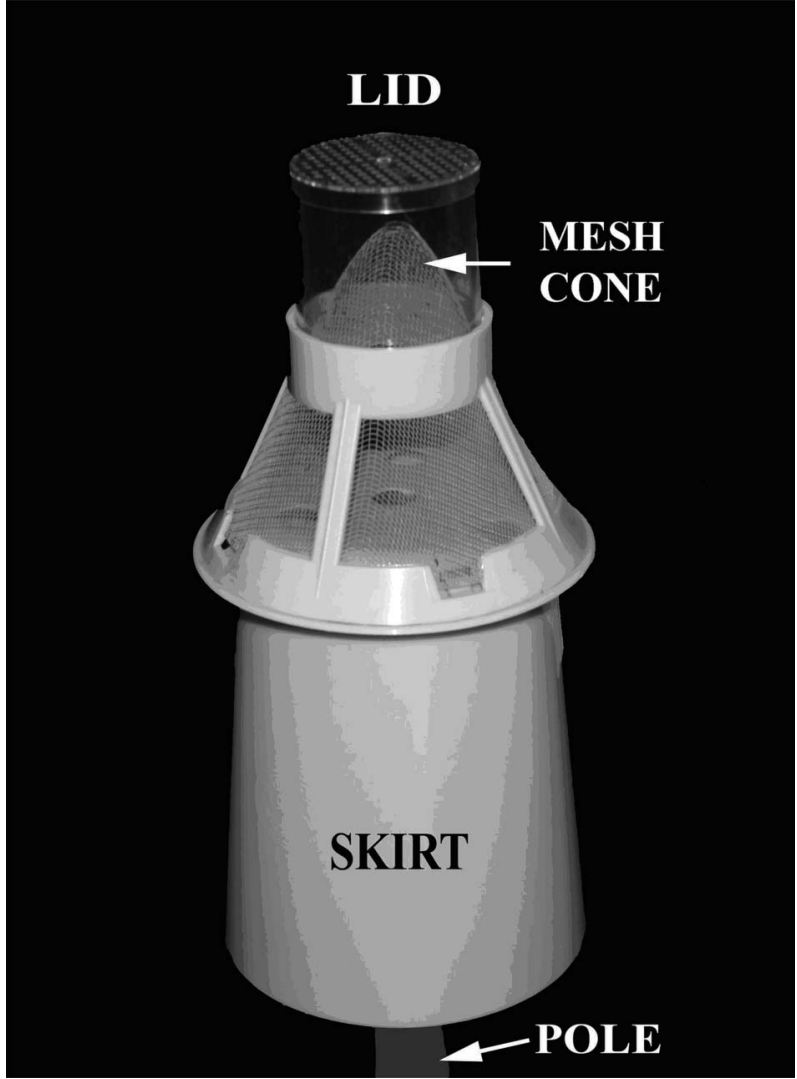

Figure 2. A photograph of a boll weevil trap with the four locations of the trap assembly labelled.

washed twice in soapy water. The soapy water was removed by rinsing the first time with tap water and the second time with distilled water. Next, two rinses were made with $100 \%$ ETOH (ethyl alcohol). The traps and poles were allowed to dry under paper towels. Once dry, traps and pole were placed into separate sterile plastic bags and sealed until installed in the field. A control trap and pole was also set out in the field to determine if pollen was entirely removed from the trap and pole.

\section{Pollen collection}

Cleaned traps were set out during January. During February the original trap was wiped for pollen, and replaced with a newly cleaned trap. The replacement trap was left for three days then wiped. The original trap was returned to the lab and cleaned. After the replacement trap was wiped, it was removed and the cleaned original trap was put back into place until the next month. No pheromone lures were put into the traps.

A clean $45 \mathrm{~mm} 100 \%$ cellulose acetate filter saturated with $100 \% \mathrm{ETOH}$ was run over the parts of the trap (pole, lid, skirt, and mesh cone). A new sterile filter was used for each wipe.
Sterile plastic gloves were used when handing the wipes to prevent pollen contamination from one's hands. Wipes were made by holding the wipe and running it over, or around the trap part. The pole was sampled about $0.75 \mathrm{~m}$ from the ground. The skirt was wiped about $2 \mathrm{~cm}$ from the bottom edge. The entire lid and mesh cone were wiped. Each filter was placed into individually marked, sterile zip-top plastic bags immediately after each wipe and frozen until processed.

\section{Pollen analyses}

Filters were allowed to thaw in the plastic bag for 15 minutes. As a marker, one Lycopodium clavatum L. tablet containing $10379 \pm 953$ spores was dissolved in $1 \mathrm{ml}$ of $10 \%(\mathrm{~V} / \mathrm{V}) \mathrm{HCl}$. Another $1 \mathrm{ml}$ of $10 \% \mathrm{HCl}$ was added to the beaker and the beaker was gently shaken until the tablet completely dissolved. One $\mathrm{ml}$ of water was added to the beaker and the spores were transferred into uniquely marked 15 $\mathrm{ml}$ glass centrifuge tubes. Enough water was added to fill the test tube. The test tubes were centrifuged at $1060 \times \mathrm{g}$ for $3 \mathrm{~min}$, the supernatant decanted, and the remaining spores were vortexed. The test tubes were rinsed two more times with distilled water, centrifuged, decanted, and vortexed each time.

The thawed filters were carefully rolled into a slender tube shape and placed into a test tube with the dissolved spores. Five mls of glacial acetic acid was added to start the deterioration process of the filters and remove any water. The samples were centrifuged, decanted, and vortexed. Five mls of a 9:1 ratio of acetic anhydride to sulfuric acid was added to the samples (Erdtman, 1960, 1963; Jones \& Coppedge, 1999; Jones et al., 2007). The samples were place in a preheated hot block at $100^{\circ} \mathrm{C}$. Every 3 minutes, the samples were stirred with a wooden stick. After 15 minutes, the samples were removed from the hot block and $5 \mathrm{ml}$ of glacial acetic acid was added and stirred to stop the acetolysis reaction. Samples were centrifuged, decanted, and vortexed. The samples were rinsed three times with water, centrifuging, decanting, and vortexing each time. After the water rinses, one drop of Safranin O stain was added to the samples, the samples were stirred, and then $8 \mathrm{ml}$ of $100 \% \mathrm{ETOH}$ was added. Once again the samples were centrifuged, decanted, and vortexed. Next, the samples were transferred into two dram vials, centrifuged, and decanted. Five drops of glycerin were added to each sample. The samples were placed into a warm hot block $\left(25^{\circ} \mathrm{C}\right)$ and left overnight so that the ETOH would evaporate, leaving the pollen residue in glycerin. The next day, one drop of pollen residue was placed onto a 
glass slide. A cover slip was sealed to the slide by painting the peripheral edges with nail polish.

The pollen and spores were counted separately. Once 500 spores were counted, the pollen count stopped. The Lycopodium spores and pollen counts were kept separate so that pollen concentration values could be calculated per wipe.

Totals, subtotals, and overall totals were calculated by adding the individual values. The surface area of each trap part was added together make a total surface area. Pollen concentration values per wipe were calculated by computing the ratio of marker spores to counted pollen grains using the following formula:

(No. of pollen grains counted $) \times($ No. of Lycopodium spores added)

(No. of Lycopodium counted)

An Olympus AX 70 compound light microscope was used for the pollen analyses. Pollen grains were identified to the lowest nomenclatural rank possible, family, genus, or species. Pollen from the Asteraceae (sunflower family) was divided into LS for grains with short processes or HS for grains with long processes (Jones \& Bryant, 2007; Martin, 1963). The USDA-ARS APMRU, Stanley D. and Gretchen D. Jones, David and Susan Jarzen, and Meredith Lieux pollen reference collections were used to help in the identification processes.

\section{Equalisation of the wipes}

Because the wipes from each of the four trap parts (pole, skirt, mesh cone, lid) were different sizes, the surface area and the number of pollen grains per $\mathrm{cm}^{2}$ per trap part were calculated. The parts from ten traps were measured then averaged to calculate the surface area for each part. In the formulas, $r$ equals the radius, $d$ equals the diameter, $h$ equals the height, and $S$ equals the length from the edge of the cone to the cone's apex.

The wipe on the skirt was a rectangle (length $\mathrm{X}$ width, $7.0 \times 5.0 \mathrm{~cm}$ or $35.0 \mathrm{~cm}^{2}$ ). The pole and lid are cylinder shaped. The wipe on the pole did not include the top or bottom of the pole so the formula was $\pi \mathrm{dh}\left(3.14 \mathrm{X} 1.8 \times 4 \mathrm{~cm}\right.$ or $\left.22.6 \mathrm{~cm}^{2}\right)$. The wipe on the lid included the top of the lid but not the bottom. Thus, the formula for the lid is $\pi \mathrm{dh}+\pi \mathrm{r}^{2}$ (3.14 X $5.2 \times 5.1 \mathrm{~cm}+3.14 \times 6.76 \mathrm{~cm}^{2}$, or $104.5 \mathrm{~cm}^{2}$ ). Both the outside and inside surfaces of the lid were wiped, so the surface area of the lid was multiplied by two or $209 \mathrm{~cm}^{2}$.

Since the weevils remain on the mesh cone within the lid until they are collected, only that area was wiped. The bottom of the cone was attached to the trap and is not used in the formula. The formula for the mesh cone was $\pi \mathrm{rS}(3.14 \times 2.6 \times 4.7 \mathrm{~cm}$ or $38.4 \mathrm{~cm}^{2}$ ).

\section{Results}

The cleaned, control trap and pole showed that all pollen was removed (Table I). This demonstrates that the cleaned traps and poles were pollen free prior to being used. Thus, any pollen found on them were from the plants surrounding the traps and not from the laboratory.

Initially, a 500 pollen grain count was going to be made for each wipe. However, after examining several slides, the number of pollen grains per wipe was so low that even a 200 grain count was impossible. Therefore, once the number of Lycopodium spores reached 500, the pollen grain count stopped.

\section{Brownsville and Weslaco sites}

Very little pollen was found on the traps at Brownsville (Table II). The pollen concentration values (PCV) on the skirt and the pole were the same (62.27, Table II). However, slightly more pollen per $\mathrm{cm}^{2}$ was found on the pole than on the skirt $(0.07$ and 0.04 respectively, Table II).

Like the Brownsville traps, traps at South Farms contained little pollen (Table III). The skirt of both traps contained more pollen than other parts. However, like the Brownsville wipes, the original pole contained slightly more pollen per $\mathrm{cm}^{2}$ on the skirt (0.22 and 0.17 respectively, Table III). No pollen was found on the mesh cone of either the original or the replacement traps.

Pollen taxa found on traps at Brownsville consisted of a broken Acacia sp., Asteraceae LS, Helianthus sp., Parthenium sp., she-oak (Casuarina sp.), Cheno-Am, Poaceae, and salt cedar (Tamarix sp.). Two Asteraceae LS pollen grains that were found during February, one on the pole and one on the skirt, were ghost grains. These grains most likely were blown up from the dirt road. It is not surprising that this sample picked up Casuarina and Tamarix. Although not native to Texas, both are used as

Table I. The number of Lycopodium clavatum spores (Lyco), number of pollen grains counted, pollen concentration values (PCV), number of pollen grains per $\mathrm{cm}^{2}$, and the number of taxa for the cleaned, control boll weevil trap. The mesh cone - Cone.

\begin{tabular}{lccccc}
\hline Place & Lyco & Pollen & PCV & $\mathrm{cm}^{2}$ & Taxa \\
\hline Pole & 500 & 0 & 0 & 0 & 0 \\
Lid & 500 & 0 & 0 & 0 & 0 \\
Skirt & 500 & 0 & 0 & 0 & 0 \\
Cone & 500 & 0 & 0 & 0 & 0 \\
\hline
\end{tabular}


Table II. Monthly and overall totals of the number of Lycopodium clavatum spores (Lyco), the number of pollen grains counted, the pollen concentration values (PCV), the number of pollen grains per surface area in centimetres squared $\left(\mathrm{cm}^{2}\right)$, the number of taxa for each for the original and replaced boll weevils traps near Brownsville, TX. The mesh cone - Cone. Pollen concentration values and $\mathrm{cm}^{2}$ are rounded to the nearest hundredth (0.00).

\begin{tabular}{|c|c|c|c|c|c|c|c|c|c|c|c|}
\hline \multirow[b]{2}{*}{ Month } & \multirow[b]{2}{*}{ Part } & \multicolumn{5}{|c|}{ Original trap } & \multicolumn{5}{|c|}{ Replaced trap } \\
\hline & & Lyco & Pollen & PCV & $\mathrm{cm}^{2}$ & Taxa & Lyco & Pollen & PCV & $\mathrm{cm}^{2}$ & Taxa \\
\hline \multirow[t]{5}{*}{ February } & Pole & 500 & 2 & 41.52 & 0.09 & 2 & 500 & 1 & 20.76 & 0.04 & 1 \\
\hline & Lid & 500 & 0 & 0.00 & 0.00 & 0 & 500 & 1 & 20.76 & 0.00 & 1 \\
\hline & Skirt & 500 & 2 & 41.52 & 0.06 & 2 & 500 & 1 & 20.76 & 0.03 & 1 \\
\hline & Cone & 500 & 0 & 0.00 & 0.00 & 0 & 500 & 0 & 0.00 & 0.00 & 0 \\
\hline & Total & 2000 & 4 & 83.03 & 0.01 & 4 & 2000 & 3 & 62.27 & 0.01 & 3 \\
\hline \multirow[t]{5}{*}{ March } & Pole & 500 & 1 & 20.76 & 0.04 & 1 & & & & & \\
\hline & Lid & 500 & 2 & 41.52 & 0.01 & 2 & & & & & \\
\hline & Skirt & 500 & 1 & 20.76 & 0.03 & 1 & & & & & \\
\hline & Cone & 500 & 0 & 0.00 & 0.00 & 0 & & & & & \\
\hline & Total & 2000 & 4 & 83.03 & 0.01 & 4 & & & & & \\
\hline \multirow[t]{4}{*}{ Total } & Pole & 1000 & 3 & 62.27 & 0.07 & 3 & 500 & 1 & 20.76 & 0.04 & 1 \\
\hline & $\mathrm{Lid}$ & 1000 & 2 & 41.52 & 0.00 & 2 & 500 & 1 & 20.76 & 0.00 & 1 \\
\hline & Skirt & 1000 & 3 & 62.27 & 0.04 & 3 & 500 & 1 & 20.76 & 0.03 & 1 \\
\hline & Cone & 1000 & 0 & 0.00 & 0.00 & 0 & 500 & 0 & 0.00 & 0.00 & 0 \\
\hline Overall total & & 4000 & 8 & 166.06 & 0.01 & 8 & 2000 & 3 & 62.27 & 0.01 & \\
\hline
\end{tabular}

Table III. Monthly and overall totals of the number of Lycopodium clavatum spores (Lyco), the number of pollen grains counted, the pollen concentration values (PCV), the number of pollen grains per surface area in centimetres squared $\left(\mathrm{cm}^{2}\right)$, the number of taxa for each for the original and replaced boll weevils traps at Weslaco, ARS, South Farm. The mesh cone - Cone. Pollen concentration values and $\mathrm{cm}^{2}$ are rounded to the nearest hundredth $(0.00)$.

\begin{tabular}{|c|c|c|c|c|c|c|c|c|c|c|c|}
\hline \multirow[b]{2}{*}{ Month } & \multirow[b]{2}{*}{ Part } & \multicolumn{5}{|c|}{ Original trap } & \multicolumn{5}{|c|}{ Replaced trap } \\
\hline & & Lyco & Pollen & PCV & $\mathrm{cm}^{2}$ & Taxa & Lyco & Pollen & PCV & $\mathrm{cm}^{2}$ & Taxa \\
\hline \multirow[t]{4}{*}{ April } & Pole & 500 & 5 & 103.79 & 0.22 & 2 & 500 & 1 & 20.76 & 0.04 & 1 \\
\hline & Lid & 500 & 2 & 41.52 & 0.01 & 2 & 500 & 1 & 20.76 & 0.00 & 1 \\
\hline & Skirt & 500 & 6 & 124.55 & 0.17 & 3 & 500 & 4 & 83.03 & 0.11 & 3 \\
\hline & Cone & 500 & 0 & 0.00 & 0.00 & 0 & 500 & 0 & 0.00 & 0.00 & 0 \\
\hline Overall total & & 2000 & 13 & 269.85 & 0.04 & 7 & 2000 & 6 & 124.55 & 0.02 & 5 \\
\hline
\end{tabular}

ornamentals and can be found in various areas in the Lower Rio Grande Valley. There were about ten Casuarina trees planted along a paved road approximately $2.2 \mathrm{~km}$ west of the trap. As for the Tamarix, a large salt cedar occurred about $1 \mathrm{~km}$ west of the trap.

Little pollen diversity was found on the South Farm traps. Two Carya illinoinensis (pecan) pollen grains were found on the skirt of the original trap. Other taxa include two different Asteraceae LS, Poaceae, and Cheno-Am.

\section{Santa Ana sites}

During February, both the original and the replacement traps on the Old Cemetery Trail contained little pollen and few taxa (Table IV). During March, the replacement trap contained more than twice the number of pollen grains than the original trap (43 and 19 respectively). However, during April, the original trap contained more pollen than the replacement (42 and 26 respectively) (Table IV). Pollen was found on the mesh cone only during March and only one grain was found on the original and the replacement traps (Table IV). Overall, the skirt had the greatest number of pollen grains encountered and per $\mathrm{cm}^{2}$, and the greatest pollen diversity than any other trap part on either trap (Table IV).

Traps placed on Bobcat Trail had results similar to that at Old Cemetery. The fewest number of pollen grains and least pollen taxa diversity were found during February and the greatest during March (Table V). The skirt of the original trap during March had the greatest number of pollen grains (66) while the pole during March had the greatest number of pollen grains per $\mathrm{cm}^{2}$ (2.17) (Table V). Overall, more pollen was found on the skirt (110 grains) of the original trap, but the pole of the 
Table IV. Monthly and overall totals of the number of Lycopodium clavatum spores (Lyco), the number of pollen grains counted, the pollen concentration values (PCV), the number of pollen grains per surface area in centimetres squared $\left(\mathrm{cm}^{2}\right)$, the number of taxa for each for the original and replaced boll weevils traps at the Old Cemetery Trail, Santa Ana Wildlife Refuge. The mesh cone - Cone. Pollen concentration values and $\mathrm{cm}^{2}$ are rounded to the nearest hundredth $(0.00)$.

\begin{tabular}{|c|c|c|c|c|c|c|c|c|c|c|c|}
\hline \multirow[b]{2}{*}{ Month } & \multirow[b]{2}{*}{ Part } & \multicolumn{5}{|c|}{ Original trap } & \multicolumn{5}{|c|}{ Replaced trap } \\
\hline & & Lyco & Pollen & PCV & $\mathrm{cm}^{2}$ & Taxa & Lyco & Pollen & PCV & $\mathrm{cm}^{2}$ & Taxa \\
\hline \multirow[t]{5}{*}{ February } & Pole & 500 & 1 & 20.76 & 0.04 & 1 & 500 & 0 & 0.00 & 0.00 & 0 \\
\hline & Lid & 500 & 1 & 20.76 & 0.00 & 1 & 500 & 0 & 0.00 & 0.00 & 0 \\
\hline & Skirt & 500 & 0 & 0.00 & 0.00 & 0 & 500 & 0 & 0.00 & 0.00 & 0 \\
\hline & Cone & 500 & 0 & 0.00 & 0.00 & 0 & 500 & 0 & 0.00 & 0.00 & 0 \\
\hline & Total & 2000 & 2 & 41.52 & 0.01 & 2 & 200 & 0 & 0.00 & 0.00 & 0 \\
\hline \multirow[t]{5}{*}{ March } & Pole & 500 & 3 & 62.27 & 0.13 & 3 & 500 & 3 & 62.27 & 0.13 & 2 \\
\hline & Lid & 500 & 2 & 41.52 & 0.01 & 1 & 500 & 2 & 41.52 & 0.01 & 2 \\
\hline & Skirt & 500 & 13 & 269.85 & 0.37 & 8 & 500 & 37 & 768.05 & 1.06 & 8 \\
\hline & Cone & 500 & 1 & 20.76 & 0.03 & 1 & 500 & 1 & 20.76 & 0.03 & 1 \\
\hline & Total & 2000 & 19 & 394.40 & 0.06 & 10 & 2000 & 43 & 892.594 & 0.14 & 9 \\
\hline \multirow[t]{5}{*}{ April } & Pole & 500 & 4 & 83.03 & 0.18 & 4 & 500 & 4 & 83.03 & 0.18 & 2 \\
\hline & Lid & 500 & 14 & 290.61 & 0.07 & 8 & 500 & 3 & 62.27 & 0.01 & 3 \\
\hline & Skirt & 500 & 24 & 498.19 & 0.69 & 13 & 500 & 19 & 394.40 & 0.54 & 11 \\
\hline & Cone & 500 & 0 & 0.00 & 0.00 & 0 & 500 & 0 & 0.00 & 0.00 & 0 \\
\hline & Total & 2000 & 42 & 871.84 & 0.14 & 18 & 2000 & 26 & 539.71 & 0.09 & 14 \\
\hline \multirow[t]{4}{*}{ Total } & Pole & 1500 & 8 & 166.06 & 0.12 & 5 & 1500 & 7 & 145.31 & 0.10 & 4 \\
\hline & Lid & 1500 & 17 & 352.89 & 0.03 & 8 & 1500 & 5 & 103.79 & 0.01 & 5 \\
\hline & Skirt & 1500 & 37 & 768.05 & 0.35 & 20 & 1500 & 56 & 1162.45 & 0.53 & 13 \\
\hline & Cone & 1500 & 1 & 20.76 & 0.00 & 1 & 1500 & 1 & 20.76 & 0.01 & 1 \\
\hline Overall total & & 6000 & 63 & 1307.75 & 0.07 & 23 & 6000 & 69 & 1432.30 & 0.08 & 17 \\
\hline
\end{tabular}

Table V. Monthly and overall totals of the number of Lycopodium clavatum spores (Lyco), the number of pollen grains counted, the pollen concentration values (PCV), the number of pollen grains per surface area in centimetres squared $\left(\mathrm{cm}^{2}\right)$, the number of taxa for each for the original and replaced boll weevils traps at the Bobcat Trail, Santa Ana Wildlife Refuge, The mesh cone - Cone. Pollen concentration values and $\mathrm{cm}^{2}$ are rounded to the nearest hundredth $(0.00)$.

\begin{tabular}{|c|c|c|c|c|c|c|c|c|c|c|c|}
\hline \multirow[b]{2}{*}{ Month } & \multirow[b]{2}{*}{ Part } & \multicolumn{5}{|c|}{ Original trap } & \multicolumn{5}{|c|}{ Replaced trap } \\
\hline & & Lyco & Pollen & PCV & $\mathrm{cm}^{2}$ & Taxa & Lyco & Pollen & PCV & $\mathrm{cm}^{2}$ & Taxa \\
\hline \multirow[t]{5}{*}{ February } & Pole & 500 & 0 & 0.00 & 0.00 & 0 & 500 & 0 & 0.00 & 0.00 & 0 \\
\hline & Lid & 500 & 1 & 20.76 & 0.00 & 1 & 500 & 0 & 0.00 & 0.00 & \\
\hline & Skirt & 500 & 3 & 62.28 & 0.09 & 2 & 500 & 0 & 0.00 & 0.00 & \\
\hline & Cone & 500 & 0 & 0.00 & 0.00 & 0 & 500 & 0 & 0.00 & 0.00 & 0 \\
\hline & Total & 2000 & 4 & 83.03 & 0.01 & 3 & 2000 & 0 & 0.00 & 0.00 & \\
\hline \multirow[t]{5}{*}{ March } & Pole & 500 & 49 & 1017.14 & 2.17 & 14 & 500 & 1 & 20.76 & 0.04 & 1 \\
\hline & Lid & 500 & 16 & 332.13 & 0.08 & 8 & 500 & 6 & 124.55 & 0.03 & 4 \\
\hline & Skirt & 500 & 66 & 1370.03 & 1.89 & 15 & 500 & 24 & 498.19 & 0.69 & 15 \\
\hline & Cone & 500 & 7 & 145.30 & 0.18 & 6 & 500 & 1 & 20.76 & 0.03 & 1 \\
\hline & Total & 2000 & 138 & 2864.60 & 0.45 & 32 & 2000 & 32 & 664.26 & 0.10 & 17 \\
\hline \multirow[t]{5}{*}{ April } & Pole & 500 & 31 & 634.50 & 1.37 & 12 & 501 & 11 & 227.88 & 0.49 & 7 \\
\hline & Lid & 502 & 29 & 599.58 & 0.14 & 12 & 500 & 25 & 518.95 & 0.12 & 13 \\
\hline & Skirt & 500 & 41 & 851.08 & 1.17 & 10 & 500 & 19 & 394.40 & 0.54 & 8 \\
\hline & Cone & 500 & 5 & 103.79 & 0.13 & 4 & 500 & 0 & 0.00 & 0.00 & 0 \\
\hline & Total & 2002 & 106 & 2198.15 & 0.35 & 25 & 2001 & 55 & 1141.12 & 0.18 & 22 \\
\hline \multirow[t]{4}{*}{ Total } & Pole & 1500 & 80 & 1660.64 & 1.18 & 24 & 1500 & 12 & 248.93 & 0.18 & 8 \\
\hline & Lid & 1500 & 46 & 953.60 & 0.07 & 23 & 1500 & 31 & 643.50 & 0.05 & 14 \\
\hline & Skirt & 1500 & 110 & 2283.38 & 1.05 & 19 & 1500 & 43 & 892.59 & 0.41 & 18 \\
\hline & Cone & 1500 & 12 & 249.10 & 0.10 & 6 & 1500 & 1 & 20.76 & 0.01 & 1 \\
\hline Overall total & & 6002 & 248 & 5146.27 & 0.27 & 38 & 6001 & 87 & 1806.08 & 0.10 & 29 \\
\hline
\end{tabular}


Table VI. Overall totals for the baseline and replacement boll weevil traps at Santa Ana Wildlife Refuge (Old Cemetery and Bobcat Trail sites). The number of Lycopodium clavatum spores (Lyco), the number of pollen grains counted (pollen), the pollen concentration values (PCV) and the number of taxa for the initial boll weevil trap control are totaled. The mesh cone - Cone. Pollen concentration values and $\mathrm{cm}^{2}$ are rounded to the nearest hundredth (0.00).

\begin{tabular}{llrrrrr}
\hline & Part & Lyco & Pollen & PCV & $\mathrm{cm}^{2}$ & Taxa \\
\hline Original & Pole & 3000 & 88 & 1826.70 & 0.65 & 26 \\
& Lid & 3002 & 63 & 1306.88 & 0.05 & 27 \\
& Skirt & 3000 & 147 & 3051.43 & 0.70 & 28 \\
& Cone & 3000 & 13 & 269.85 & 0.10 & 6 \\
& Total & 12002 & 311 & 6454.66 & 0.17 & 46 \\
Replaced & Pole & 3001 & 19 & 394.27 & 0.14 & 13 \\
& Lid & 3000 & 36 & 747.29 & 0.03 & 17 \\
& Skirt & 3000 & 75 & 1556.85 & 0.47 & 28 \\
& Cone & 30001 & 2 & 41.50 & 0.01 & 2 \\
& Total & 12001 & 158 & 3279.49 & 0.09 & 37 \\
& Pole & 6001 & 107 & 2220.74 & 0.39 & 30 \\
& Lid & 6002 & 99 & 2054.35 & 0.04 & 34 \\
& Skirt & 6000 & 246 & 5106.47 & 0.59 & 37 \\
& Cone & 6000 & 15 & 311.37 & 0.03 & 8 \\
& Total & 24003 & 467 & 9692.77 & 0.13 & 51 \\
\hline
\end{tabular}

original trap had the greatest number of pollen grains per $\mathrm{cm}^{2}(1.18$, Table V).

When combining the results from the traps at the Old Cemetery and Bobcat Trail, the original trap contained more pollen grains (311), a higher pollen concentration value (6454.66), a greater number of pollen grains per $\mathrm{cm}^{2}(0.17)$, and a greater pollen taxa diversity (46) than the replacement trap (Table VI). The skirt of both traps was the most pollen contaminated of all the trap parts. It had the greatest number of pollen grains (246), the highest pollen concentration value (5106.47), the greatest number of pollen grains per $\mathrm{cm}^{2}(0.59)$, and the highest pollen diversity (37) of any other trap part (Table VI). Overall, the mesh cone contained the least amount of pollen (15) and the lowest pollen diversity (8) (Table VI).

A total of 467 pollen grains representing 51 taxa were counted from the wipes taken at Santa Ana (Table VI). Of the taxa that were represented with two or more pollen grains, Celtis laevigata, Leucaena sp., Poaceae, and Prosopis glandulosa were found at both Santa Ana sites (Table VII). Leucaena sp. was found during all three months, however, it was not always found on the same part of the trap. Taxa that are more water loving, Salix nigra H. Marshall, Sesbania sp., and several others that were represented with only one pollen grain, were found on the wipes from the Bobcat Trail and not on wipes from traps at the Old Cemetery. The majority of the pollen found on the traps at Santa Ana were from woody plants.

\section{Discussion}

To ensure that any pollen found on the trap parts were contaminants, the trap had to be pollen-free when installed. The two soapy water washes and the two ETOH washes removed all of the pollen on the test trap. This ensured that pollen from the laboratory or from Weslaco did not contaminate the traps prior to use. Whether this cleaning process can be shortened is not known.

The Lycopodium spores were added for several reasons. First, by adding a known number of spores, the pollen concentration values could be calculated. Although the surface area of the pole, skirt, and mesh cone were similar $\left(22.6,35.0,38.4 \mathrm{~cm}^{2}\right.$, respectively), the area of the lid was larger (209 $\mathrm{cm}^{2}$ ). Adding the marker spores to the sample and calculating the pollen concentration values per wipe allows comparison among the different wipes.

Second, the spores were a control. If the spores were not added and no pollen was found in a sample, it is not known if the sample did not contain pollen or if there was a problem with the pollen recovery. If the spores are added but no pollen is found in the sample, then the technique used to recover pollen from the sample was okay and the sample just did not have any pollen.

Maher (1981) indicated that the ratio of pollen grains in a sample should not exceed twice the number of tracer spores added before processing. The most efficient pollen/marker ratio that gives the greatest precision for the least amount of counting is when the ratio of pollen to tracer spores is at or close to $2: 1$. Furthermore, the greater the ratio of pollen to tracer spores beyond 2:1, the larger number of pollen and tracer spores must be counted to obtain the same level of accuracy provided by smaller counts with ratios of $2: 1$ or less.

In the beginning, it was expected that a 200 or 500 grain count would be made depending on the amount of pollen in the pollen residue. Previous studies of surface samples (Bryant et al., 1994; Mack \& Bryant, 1974; and others) contained no more than $20000-25000$ pollen grains per gram. When a sample is pollen rich and only a minimal number of tracer spores are added, encountering even one additional tracer spore during a count drastically changed the pollen concentration value (Maher, 1981). However, in our research, the number of pollen grains encountered from a single wipe was so small that the number of spores in one tablet seemed to overwhelm the number of pollen grains.

After examining the first couple of slides, the number of pollen grains was so low that it was obvious that a 200 grain count would be impossible. 
Table VII. Taxa of pollen with two or more pollen grains during each month for the wipes taken from the original and replacement traps on the Old Cemetery and Bobcat Trails in Santa Ana Wildlife refuge by month. P - pole, L lid, $\mathrm{S}$ - skirt, and $\mathrm{T}-$ mesh cone.

\begin{tabular}{|c|c|c|c|c|c|c|}
\hline & \multicolumn{3}{|c|}{ Original trap } & \multicolumn{3}{|c|}{ Replacement trap } \\
\hline & February & March & April & February & March & April \\
\hline \multicolumn{7}{|l|}{ Old Cemetery Trail } \\
\hline Acer sp. & & & $\mathrm{L}, \mathrm{S}$ & & & S \\
\hline Celtis laevigata & & & S & & & \\
\hline Chenop.-Amaranth. & & $S$ & $S$ & & & \\
\hline Diospyros texana & & & $\mathrm{S}$ & & & \\
\hline Fraxinus sp. & & $S$ & & & $\mathrm{P}, \mathrm{S}$ & $\mathrm{T}$ \\
\hline Leucaena sp. & & $\mathrm{L}$ & $\mathrm{L}$ & & $\mathrm{P}, \mathrm{S}$ & $\mathrm{T}$ \\
\hline Poaceae & & & $\mathrm{L}$ & & S & S \\
\hline Prosopis glandulosa & & $S$ & & & S & \\
\hline \multicolumn{7}{|l|}{ Bobcat Trail } \\
\hline Acacia sp. & & $\mathrm{P}$ & & & & $S$ \\
\hline Asteraceae LS & & $S$ & & & & \\
\hline Castanea sp. & & $\mathrm{L}$ & & & & \\
\hline Celtis laevigata & & $\mathrm{P}, \mathrm{S}$ & $\mathrm{P}$ & & $\mathrm{L}, \mathrm{S}$ & $\mathrm{L}$ \\
\hline Diospyros virginiana & & S & $\mathrm{P}, \mathrm{S}$ & & S & \\
\hline Fabaceae & & $\mathrm{L}, \mathrm{S}$ & $\mathrm{P}$ & & & $\mathrm{P}$ \\
\hline Fraxinus sp. & & $\mathrm{P}$ & $\mathrm{L}, \mathrm{S}$ & & & $\mathrm{L}$ \\
\hline Fuglans sp. & & $S$ & & & $S$ & \\
\hline Leucaena sp. & $S$ & $\mathrm{P}$ & $\mathrm{L}, \mathrm{S}$ & & & $\mathrm{L}$ \\
\hline Neptunia sp. & & $S$ & $\mathrm{P}$ & & $S$ & \\
\hline Pinus sp. & & $\mathrm{P}$ & & & & $\mathrm{L}$ \\
\hline Poaceae & & $\mathrm{L}$ & $\mathrm{P}, \mathrm{S}$ & & S & \\
\hline Prosopis glandulosa & & $\mathrm{S}, \mathrm{T}$ & $\mathrm{P}, \mathrm{L}, \mathrm{S}$ & & $\mathrm{L}$ & $\mathrm{L}, \mathrm{S}$ \\
\hline Salix nigra & & $\mathrm{P}, \mathrm{T}$ & $\mathrm{S}, \mathrm{T}$ & & & $\mathrm{L}$ \\
\hline Sapium sebiferum & & S & & & & $\mathrm{P}, \mathrm{S}$ \\
\hline Sesbania sp. & & $\mathrm{L}$ & & & & \\
\hline Urtica sp. & & $\mathrm{L}, \mathrm{S}$ & $\mathrm{P}$ & & & \\
\hline
\end{tabular}

Therefore, it was decided that once the Lycopodium count reached 500, the pollen grain count would stop. The highest number of pollen grains encountered from a single wipe was 66 on the skirt at the Bobcat Trail in Santa Ana Wildlife Refuge during March (Table V).

Most contamination studies look at surface soil samples (Bryant et al., 1991, 1994; Mack \& Bryant, 1974: Jones \& Bryant, 2007), or pollen in the air (Cadman \& Dames, 1993; Calleja et al., 1993; Villegas \& Nolla, 2001). These types of palynological studies use a larger amount of material to begin with, and then extract the pollen from them. Sample sizes can range from $10-50 \mathrm{~g}$ for soil and honey samples to as little as $1 \mathrm{~g}$ in forensic studies (Mildenhall et al., 2006a, b, $c$; Horrocks, 2004, Riding et al., 2007).

Many aeropalynological studies report their pollen data in $\mathrm{cm}^{3}$ (cubic centimetres) and not $\mathrm{cm}^{2}$. Aeropalynological studies sample a large quantity of air passing though the sampler (Hart et al., 1994; Lewis et al., 1991; Käpylä \& Penttinen, 1981, to name a few). It is difficult to compare the results and concentration values from these types of studies to ours because of the different sampling techniques, amount of material used initially and the resulting values $\left(\mathrm{cm}^{3}\right.$ vs. $\left.\mathrm{cm}^{2}\right)$.

The greater the amount of material sampled, the greater the possibility of finding pollen and the greater the pollen concentration values. The material on the wipes was so little that often it looked like there was nothing on the filters at all. Of the 68 wipes that were made, over $70 \%$ had pollen concentration values less than 100 (calculated from Tables II-V).

Pollen concentration values in honey are usually very high and pollen grain counts of over 500 grains are easily made. As a single example of pollen concentration values in honey, Jones and Bryant (2004) examined various techniques for dissolving honey. The pollen concentration values of the honey they examined ranged from 5650.00 to 213207.55 per gram of honey.

The highest pollen concentration value of this study was 9693 for all 48 wipes (at Santa Ana sites (Table VI). This includes wipes of both the original and replaced trap. The highest pollen concentration value for a single trap part was 1370 , on the skirt during March at the Bobcat Trail in Santa Ana (Table V). 
Pollen contamination has become the focus for forensic palynology (Bryant \& Jones, 2006; Horrocks, 2004; Horrocks \& Walsh, 1998; Mildenhall, 2006b; Milne et al., 2005; Montali, et al., 2006; Rawlins et al., 2006; Wiltshire, 2006). However, for most forensic palynological work, samples are vacuumed from clothing, vehicles, dwellings or the entire object can be submersed in $10 \%$ potassium hydroxide (Horrocks, 2004).

The benefit of vacuuming is that a larger area can be sampled to obtain a greater number of pollen grains and obtain a better pollen assemblage. The larger the surface area, the greater the number of pollen grains that can be collected and the greater the possibility of finding a taxon that links to a particular habitat. For most forensic palynological samples, there are enough pollen grains to make a 200 - 500 grain count (Mildenhall, 2006a, b, c; Jones \& Bryant, 2007; Milne et al., 2005; Riding et al., 2007; Wiltshire, 2006).

Overall, the pollen data values were lowest on the traps at Brownsville and South Farm (Tables II and III) and highest at Santa Ana, especially on the traps at Bobcat Trail (Tables IV-VI). Although more pollen was found on the trap parts in Santa Ana, the number of pollen grains is still very low (Tables II-V).

Except during March at the Old Cemetery, the replacement trap contained less pollen than the original trap (Tables II-VI). It is expected that the replacement trap will contain fewer pollen grains because it was left in place only three days while the original trap was left in place for 30 days. What happened during March at the Old Cemetery to make the replacement trap more contaminated that the original trap is unknown. There are many things that could have affected this trap including being touched by the public or animals, cutting down or clearing of the trail, etc. Although the trap was placed inconspicuously along the trail, it was not hidden and could be seen by anyone hiking that part of the trail.

The mesh cone where trapped weevils stay until collected contained the least number of pollen grains, lowest pollen concentration values, lowest number of grains per $\mathrm{cm}^{2}$, and the least pollen diversity regardless of the site (Tables II-IV). How wind currents that blow through the lid and the mesh cone, rain events, etc. affect the number of pollen grains and the pollen retention on the mesh cone are not known.

The three sites were chosen because of habitat differences among them. The Brownsville site represented more of a saline habitat with few woody plant taxa. Since the Brownsville site was so severely disturbed, a site at Weslaco (USDA-ARS
South Farm) was chosen that was as similar as possible. The Weslaco site was less saline and contained more woody vegetation. However, there was not the diversity of woody vegetation at Weslaco as at Santa Ana. Regardless, the Weslaco site was a typical trap placement along the border of a cotton field.

Santa Ana was chosen because of the diversity of vegetation, both woody and herbaceous. Santa Ana represents a more "natural" habitat as compared to a cotton field, and one that was not as disturbed. Although the majority of boll weevil traps are not placed in this type of habitat, some are. The majority of boll weevil traps are placed along cotton and other crop fields, cropping roads or the side of the highway.

The pollen found on the traps at Brownsville and Weslaco had very low pollen diversity. This is not surprising because the plant diversity in the Brownsville and Weslaco locations is much less than that of Santa Ana. Additionally, the traps at Brownsville and Weslaco were next to old cotton fields that were fallow at the time.

At Santa Ana, the traps were placed in clearings on trails that were surrounded by thick, woody and herbaceous vegetation. The number of plants and diversity of taxa within Santa Ana are much greater than that of Brownsville or Weslaco. Thus, it is not surprising that the traps in Santa Ana would have the greatest pollen data.

Although not the main focus of this study, the pollen diversity of the different study sites did reflect the plant diversity of the surrounding habitats. More herbaceous taxa were found on the traps at Brownsville and South Farm than at Santa Ana. Likewise, more pollen from woody taxa was found on traps at Santa Ana. Some taxa found on the traps at Bobcat Trail were more water-loving than those at the Old Cemetery. This is not surprising because ponds at Santa Ana were not far from the Bobcat Trail site.

\section{Conclusions}

The focus of this study was to examine the pollen contamination of a boll weevil trap to determine if the weevils might become contaminated with pollen while waiting in the trap prior to collection. One of the challenges of conducting research that has not been previously reported is determining what techniques work and what do not, what things to include and what to leave out, and why the results turned out as they did.

Using the wipes is very easy and little is needed in the way of equipment and supplies for this technique. For future research using the wipe technique, 
we suggest two things. First, a larger surface area should be sampled or wiped. This will increase the pollen data, specially the pollen count and pollen diversity. For our type of research, sampling a larger surface area is easy. However, for other palynological research, such as forensic palynology, it may be impossible and/or too obvious to wipe a larger surface area.

Calculating the pollen number per $\mathrm{cm}^{2}$ may be the only way of determining how contaminated an object is and the only way to compare wipes of various sizes, especially in sensitive areas where a larger sample size is impossible to obtain. This technique would be beneficial when a vacuum is not available or can not be used.

We also suggest when possible to collect a soil sample along with the wipe. The pollen residue from the soil sample could then be used as a comparison to see how much the sample was contaminated. This type of comparison would help account for and show any differences among taxa found on the wipes and determine the retention of pollen on various surfaces.

As far as techniques are concerned, using the $100 \%$ cellulose acetate filters is easy. The supplies needed are the filters, gloves, and alcohol. The filters can be purchased in various sizes and dissolve easily during acetolysis. They are packaged in 100s. Each filter is separated by a cardboard disk that keeps the filters below pollen free. Unfortunately, in the USA, this type of filter ( $100 \%$ cellulose acetate) can be obtained from only one company. Jones and Bryant (1998) reported finding filter fragments when examining filtered honey samples with scanning electron microscopy. We did not find any filter fragments when examining the samples with light microscopy but if SEM if going to be used, then additional processing may be necessary when using this technique.

Putting the filters into $1.5 \mathrm{ml}$ eppendorf tubes would make processing easier, less costly, and the entire amount of pollen residue easily could be examined. However, if Lycopodium spores are added, either the spores need to be added after the tablet is dissolved and rinsed or larger (12 or $15 \mathrm{ml}$ ) centrifuge tubes need to be used. The Lycopodium tablets will effervesce over the top of the eppendorf tube when the tablets are dissolved with acid (Jones \& Bryant, 1998).

The traps at Brownsville and South Farm represent the normal placement of weevil traps, and little pollen was found on the traps. When traps were placed in areas with a greater diversity of plant taxa, the number of pollen grains per $\mathrm{cm}^{2}$ increased from zero (Tables II and III) to two (Table V) for the original trap that was left in place for one month. The pole at Bobcat Trail at Santa
Ana was the most contaminated trap part $(2.17$ $\mathrm{cm}^{2}$ ) of the study (Table V). The pole is made of metal while the other trap parts are plastic. The roughness of the pole most likely allowed places where pollen grains could be trapped. However, weevils seldom land on the pole and walk upwards to the trap.

The fact that the trap parts contained so little pollen indicates that it is doubtful that weevils are contaminated by non-food pollen as they enter and remain in the trap. Regardless, we recommend that for palynological research insects be removed from traps every 24 hours.

Initially this project was going to include the examination of pollen contamination of live weevils sitting in the trap. However, because of the limitations of The Boll Weevil Eradication Program, researching live weevils "in the wild" in an Eradication Zone was out of the question. Although this research answered several questions about the pollen contamination of weevil traps, many more questions have arisen. Is pollen transferred from one adult weevil to another while they are trapped? What is the longevity of the pollen found on the trap parts? Does a pollen grain's ornamentation aid or hinder its adherence on an insect trap? Do various materials (plastic, wood, metal, etc.) collect more or less pollen? Many of these questions can easily be answered and will help improve our understanding of pollen contamination levels on trapped boll weevils. Unfortunately, if live weevils are used to answer some of these questions, the research will have to be conducted out of the USA because of the Boll Weevil Eradication Program.

\section{Acknowledgements}

We appreciate Ester F. Wilson (USDA-ARS, APMRU) for her untiring assistance in this research and the photograph of the boll weevil trap. We also are indebted to Drs. Vaughn M. Bryant, Jr., (Texas A \& M University) and Cynthia Sheffield (United States Department of Agriculture, Agriculture Research Service, Food and Feed Safety Research Unit) for their editorial comments. A special thanks goes to Santa Ana Wildlife Refuge and the US Department of Interior for allowing us to do this research in the refuge, permit number 21551-102805-BKM, Station No. 21551. We appreciate the work of the reviewers selected by Grana that helped improve this manuscript. Mention of trade names or commercial products in this article is solely for the purpose of providing specific information and does not imply recommendation or endorsement by the US Department of Agriculture. 


\section{References}

Bariola, L. A., Henneberry, T. J. \& Bergman, D. (1984). Boll weevil (Coleoptera: Curculionidae) emergence from bolls during the spring, and trapping of adults in Arizona. $f$ Econ. Entomol., 77, 1166-1170.

Benedict, J. H., Wolfenbarger, D. A., Bryant, V. M., Jr. \& George, D. M. (1991). Pollens ingested by boll weevils (Coleoptera: Curculionidae) in southern Texas and northeastern Mexico. 7. Econ. Entomol., 84, 126-131.

Bryant, V. M. Jr. \& Jones G. D. (2006). Forensic palynology: Current status of a rarely used technique in the United States of America. For. Sci. Intl., 163, 183-197.

Bryant, V. M., Jr., Holloway, R. G., Jones, J. G. \& Carlson, D. L. (1994). Pollen preservation in alkaline soils of the American Southwest. In A. Traverse (Ed.), Sedimentation of organic particles (pp. 47-58). Cambridge, UK: Cambridge Univ. Press.

Bryant, V. M. Jr., Pendleton, M., Murray, R. E., Lingren, P. D. \& Raulston, J. R. (1991). Techniques for studying pollen adhering to nectar-feeding corn earworm (Lepidoptera: Noctuidae) moths using scanning electron microscopy. F. Econ. Entomol., 84, 237-240.

Cadman, A. \& Dames, J. F. (1993). Airspora of Durban: A subtropical, coastal South African city. Grana, 32, 372-375.

Calleja, J., Rossignol-Strick, M. \& Duzer, D. (1993). Atmospheric pollen content off West Africa. Rev. Paleobot. Palynol., 79, 335-368.

Cate, J. R. \& Skinner, J. L. (1978). The fate and identification of pollen in the alimentary canal of the boll weevil. SW Entomol., 3, 263-265.

Correll, D. S. \& Johnston, M. C. (1979). Manual of the vascular plants of Texas. Austin, TX: Texas Univ. Press.

Cross, W. H., Lukefahr, M. J., Fryxell, P. A. \& Burke, H. R. (1975). Host plants of the boll weevil. Environ. Entomol., 4, 19-26.

Cuadrado, G. A. (1996). Comportaminento alimentario del picudo del algodonero, Anthonomus grandis B. Palinologia I. In T. Stadler (Ed.), Semin. Int. Manejo integrado del picudo del algodonero en Argentina, Brasil, y Paraguay. Londrina IAPAR 1995. Actas Semin. (pp. 123-126). Buenos Aires: Inst. Argent. Sanid. Calid Veg.

Cuadrado, G. A. (1999). Alimentación de Anthonomus grandis B. (Coleoptera: Curculionidae) en la provincia de Misiones, Argentina. Analisis palinologico. Natura Neotrop., 30, 43-50.

Cuadrado, G. A. (2002). Anthonomus grandis Boheman (Coleoptera: Curculionidae) en la Zona Central y Sur Oeste de Misiones, Argentina; polen como fuente alimenticia y su relatión con et estado fisiológico en insectos adultos. Neotrop. Entomol., 31, 121-132.

Cuadrado, G. A. \& Garralla, S. S. (2000). Plantas alimenticias alternativas del picudo del algodonero (Anthonomus grandis $\mathrm{B}$. Coleoptera: Curculionidae) en la provincia de Formosa, Argentina. Análisis del tracto digestivo. An. Soc. Entomol. Brasil, 29, 254-255.

Erdtman, G. (1960). The acetolysis method. Sv. Bot. Tidskr., 54, 561-564.

Erdtman, G. (1963). Palynology. In R. D. Preston (Ed.), Advances in Botanical Research, Vol. 1 (pp. 149-208). London: Acad. Press.

Gabriel, D. (2000). Biologia del picudo del algodonero Anthonomus grandis Boh., 1843, en hospederas alternantes a través de la oviposición artificial. In CFC Ed. Comm. (Eds), $3^{\text {rd }}$ Semin. Int. Manejo Integrado del Picudo del Algodonero en Argentina, Brasil y Paraguay. Ribeirão Preto, 1999. Actas Semin. (pp. 59-62). Ribeirão Preto, SP: CFC/ICAC.

Gaines, R. D. (1934). The development of the boll weevil on plants other than cotton. F. Econ. Entomol., 27, 745-748.

Hardee, D. D., Jones, G. D. \& Adams, L. C. (1999). Emergence, movement, and host plants of boll weevils (Coleoptera:
Curculionidae) in the Delta of Mississippi. F. Econ. Entomol., 92, 130-139.

Hart, J. L., Wentworth, J. E. \& Bailey, J. (1994). The effects of trap height and weather variable on recorded pollen concentration at Leicester. Grana, 33, 100-103.

Horrocks, M. (2004). Sub-sampling and preparing forensic samples for pollen analysis. F. For. Sci., 49, 1-4.

Horrocks, M. \& Walsh, K. A. (1998). Forensic palynology: Assessing the value of the evidence. Rev. Palaeobot. Palynol., 103, 69-74.

Jones, R. W. (1997). Pollen feeding by the boll weevil (Coleoptera: Curculionidae) following cotton harvest in East Central Texas. SW Entomol., 22, 419-429.

Jones, G. D. \& Bryant, V. M., Jr. (1998). Pollen recovery from honey. In Bryant, V. M. \& Wrenn, J. H. (Eds), New developments in palynomorph sampling, extraction, and analysis (pp. 107-114). Dallas, TX: Am. Assoc. Stratigr. Palynol. Found. AASP Contrib. Ser. 33.

Jones, G. D. \& Bryant, V. M., Jr. (2004). The use of ETOH for the dilution of honey. Grana, 43, 174-182.

Jones, G. D. \& Bryant, V. M., Jr. (2007). A comparison of pollen counts: Light versus scanning electron microscopy. Grana, 46, 20-33.

Jones, G. D. \& Coppedge, J. R. (1996). Pollen feeding by overwintering boll weevils. In P. Dugger \& D. Richter (Eds), Beltwide cotton production research conferences, Nashville 1996. Proceed. (pp. 979-977). Memphis, TN: NCCA.

Jones, G. D. \& Coppedge, J. R. (1999). Foraging resources of boll weevils (Coleoptera: Curculionidae). F. Econ. Entomol., 92, 860-869.

Jones, G. D., Greenberg, S. M. \& Eischen, F. A. (2007). Almond, melon, and pigweed pollen retention in the boll weevil (Coleoptera: Curculionidae). Palynology, 31, 81-93.

Jones, R. W., Cate, J. R., Hernandez, E. M. \& Sosa, E. S. (1992). Host and seasonal activity of the boll weevil (Coleoptera: Curculionidae) in tropical and sub-tropical habitats of Northeastern Mexico. F. Econ. Entomol., 85, 74-82.

Jones, R. W., Cate, J. R., Hernandez, E. M. \& Sosa, E. S. (1993). Pollen feeding and survival of the boll weevil (Coleoptera: Curculionidae) on selected plant species in Northeastern Mexico. Environ. Entomol., 22, 99-108.

Käpylä, M. \& Penttinen, A. (1981). An evaluation of the microscopic counting methods of the tape in Hirst-Burkard pollen and spore trap. Grana, 20, 131-141.

Leggett, J. E. \& Fye, R. E. (1969). The role of moisture in the winter survival of the boll weevil complex in Arizona. F. Econ. Entomol., 62, 147-149.

Lewis, W. H., Dixit, A. B. \& Wedner, H. J. (1991). Asteraceae aeropollen of the western United States Gulf Coast. Ann. Allergy, 67, 37-46.

Mack, R. N. \& Bryant, V. M., Jr. (1974). Modern pollen spectra from the Columbia Basin, Washington. NW Sci., 48, 183-194.

Maher, L. (1981). Statistics for microfossil concentration measurements employing samples spiked with marker grains. Rev. Palaeobot. Palynol., 32, 153-191.

Martin, P. S. (1963). The last thousand years, a fossil pollen record of the American southwest. Tucson, AZ: Arizona Univ. Press.

Mildenhall, D. C., Wiltshire, P. E. J. \& Bryant, V. M., Jr. $(2006 a)$. Forensic palynology: Why do it and how it works. For. Sci. Intl., 163, 163-172.

Mildenhall, D. C. (2006b). Hypericum pollen determines the presence of burglars at the scene of a crime: An example of forensic palynology. For. Sci. Intl., 163, 231-235.

Mildenhall, D. C. (2006c). An unusual appearance of a common pollen type indicates the scene of the crime. For. Sci. Int., 163, 236-240.

Milne, L. A., Bryant, V. M., Jr. \& Mildenhall, D.C. (2005). Forensic palynology. London: CRC Press. 
Montali, E., Mercuri, A. M., Grandi, G. T. \& Accorsi, C. A. (2006). Towards a "crime pollen calendar" - pollen analysis on corpses throughout one year. For. Sci. Intl., 163, 211-223.

Parrott, W. L., McKibben, G. H., Robbins, J. T. \& Villavaso, E. J. (1989). Feeding response of the boll weevil (Coleoptera: Curculionidae) to ester extracts of host plants. F. Econ. Entomol., 82, 449-453.

Rawlins, B. G., Kemp, S. J., Hodgkinson, E. H., Riding, J. B., Vane, C. H., Poulton, C. \& Freeborough, K. (2006). Potential and pitfalls in establishing the provenance of earth-related samples in forensic investigations. F. For. Sci., 51, 832-845.

Riding, J. B., Rawlis, B. G. \& Coley, K. H. (2007). Changes in soil pollen assemblages on footwear worn at different sites. Palynology, 31, 135-151.

Rummel, D. R., White, J. R. \& Pruit, G. R. (1978). A wild feeding host of the boll weevil in west Texas. SW Entomol., 3, 171-175.
Stoner, A. (1968). Sphaeralcea spp. as hosts of the boll weevil in Arizona. F. Econ. Entomol., 61, 1100-1102.

Szumkowski, W. (1953). Nota preliminar sobre Cienfuegosia heterophylla Garcke, plants hospedera de Alabama argillacea (Hbn.) y Anthonomus grandis Boh. en Venezuela. Agron. Trop. (Maracay), 1, 121.

Szumkowski, W. (1954). Lista de plantas hospedera de Anthonomus grandis Boh. en Venezuela. Agron. Trop. (Maracay), 4, 29-42.

Villegas, G. R. \& Rowe Nolla, J.-M. (2001). Atmospheric pollen in Santiago, Chile. Grana, 40, 126-132.

White, J. R. \& Rummel, D. R. (1978). Emergence profile of overwintered boll weevils and entry into cotton. Environ. Entomol., 7, 7-14.

Wiltshire, P. E. J. (2006). Consideration of some taphonomic variables of relevance to forensic palynological investigation in the United Kingdom. For. Sci. Intl., 163, 173-182. 